\title{
Impact of high non-performing loan ratios on bank lending trends and profitability
}

\author{
Eric Jing ${ }^{1}$ \\ ${ }^{1}$ Wharton School of the University of Pennsylvania
}

August 11, 2020

\begin{abstract}
The goal of this paper is to explore the relationship between the specific non-performing loan ratio (NPL ratio) and the corresponding impact on the bank's profitability and lending behavior. It also seeks to investigate the macroeconomic impacts of economies with excessively high NPL ratios as well as the efficacy and impact of alleviation measures used by banks and governments around the world to help facilitate a decrease in high NPL ratios. The possible implications and effects of the COVID-19 pandemic on NPL ratios is also addressed in this paper. It is found that when excessively high NPL ratios go unaddressed, the economy tends to suffer. On the other hand, this study shows that when measures are taken to reduce or eliminate the high NPL ratios, economic performance improves, and the reduction has a clear positive impact on the economy.
\end{abstract}

\section{Introduction}

A non-performing commercial bank loan is a loan in which the borrower has defaulted or has not made any scheduled loan payments for 90 days or more. The NPL ratio of a bank is a percentage measure of loans already at or at risk of becoming non-performing out of the total amount of loans at the bank. As research suggests, an excessively high NPL ratio causes bank to limit their credit supply to borrowers, often causing a credit supply contract ion in the immediate aftermath. Banks also risk profit loss and even bankruptcy if no measures are taken to reduce high levels of NPL ratios. At the macroeconomic level, countries with economies characterized by banks with high NPL-ratios often experience sluggish economic growth, a dramatic decrease in market confidence, increased distortion of credit allocation, sustained or increased demand of loans from borrowers, and a large contraction in available credit supply. To that end, both bank administrations as well as national governments take measures to ensure NPL ratios are kept at healthy levels. However, not all instances of high NPL ratios in modern economic history are addressed properly, and many of the NPL ratio crisis are accompanied by recessional periods in the economy. At the start of 2015 , there were 33 countries with an NPL ratio of above 10\%. Out of those 33 countries, 20 had an NPL ratio of over $15 \%$ and 11 had an NPL ratio of over $20 \%$ (refer to Figure 1 below).

Figure 1: All countries with an NPL ratio of $10 \%$ or higher as of the start of 2015 


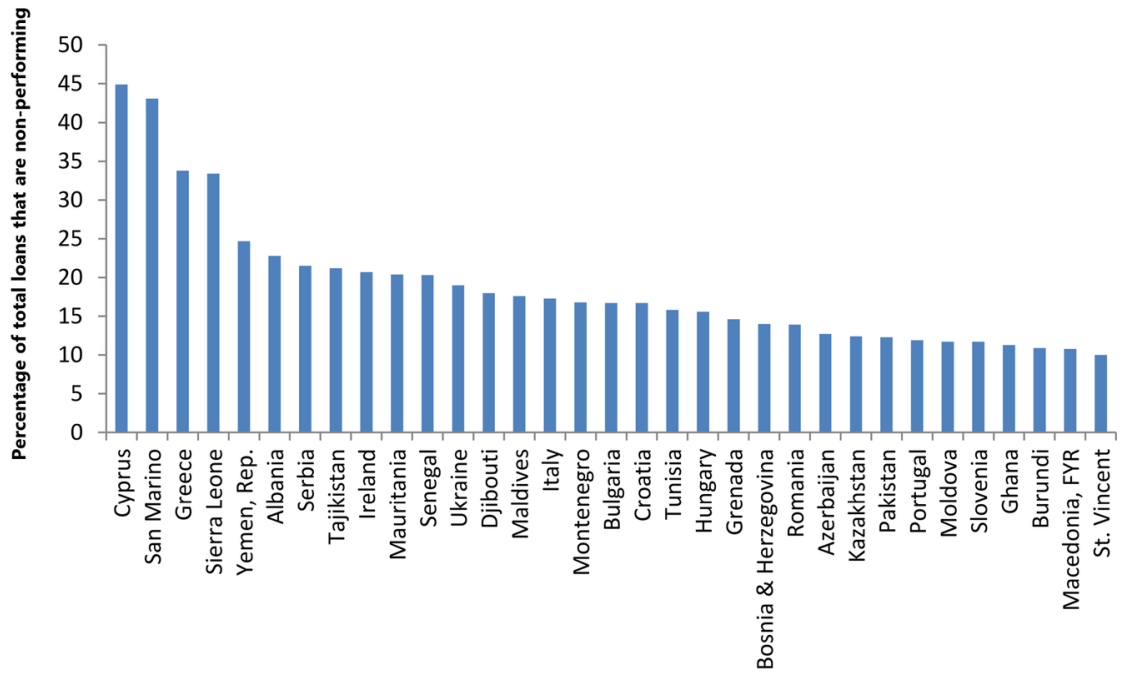

Sources: International Monetary Fund (IMF); World Economic Forum (WEF); United Nations (UN)

A close examination of these economies reveals many startling details, the first of which is that Italy and Greece - both of which are members of the O.E.C.D. and are considered developed economies - are ranked high on this list and both have excessively high NPL ratios. This is especially concerning not only for the European Union but also the world economy as it exemplifies the fragile financial system that is present in many countries - even developed economies - in the wake of the 2008-09 financial crisis and the subsequent recession and credit contraction period that followed. As legislators and policymakers around the world seek to build stronger economies and fully recover from the recession a decade ago, decreasing and maintaining a low level of non-performing loans and NPL ratio is of utmost importance. Particular economies, like that of Ukraine and Nigeria, experienced drastic fallout at the onset of the 2008-09 financial crisis, exemplified by the statistically significant uptick in their national NPL ratios (refer to Figure 2 and Figure 3). The Nigerian economy, however, quickly recovered from the financial crisis and its NPL ratio subsequently dropped back to normal. Although Nigeria is indeed seeing a new increase in its NPL ratio starting in 2015, the current NPL value of $9.300 \%$ (as of Dec. 2019) is not nearly as high as the $37.300 \%$ that was reached at the peak of the financial crisis in 2009. The Ukrainian economy, on the other hand, never fully recovered from the financial fallout in 2009, and their NPL ratio drastically increased since then. The current value of $48.400 \%$ is nearly four times as high as the $13.700 \%$ peak reached during the 2008-09 financial crisis. The stark contrast between the effect of the financial crisis and the subsequent NPL recovery provides valuable insight into the effectiveness of different types of approaches used by national governments to recover from financial crisis and, more importantly, decrease the national average NPL ratio so that banks are minimally impacted afterwards.

Figure 2: Chart of NPL ratio trends of five selected countries from 1998 to 2019

\section{[CHART]}

Sources: Government-released treasury data; International Monetary Fund (IMF)

There are also economies of interest for researchers because the average of their NPL ratio has been steadily decreasing or has taken on a significant downwards trend. The reason for these trends may be natural — no governmental actions were taken - or the result of legislative action. The Pakistani economy is an excellent example. During 1998-2003, the average NPL ratio hovered around $20 \%$ with a high of $23.400 \%$ in 2001 and a low of $17.000 \%$ in 2003. Comparing this to the 2015-2019 data, there is a significant decrease and the NPL ratio now hovers at only about $10 \%$ (refer to Figure 3) with a high of $11.359 \%$ in 2015 and a low of $9.100 \%$ in 2019 . The Russian economy experienced a similar trend when the average NPL ratio from the 
1990s (about 15\%) decreased significantly to about only $3 \%$ in the early to mid-2000s before going back up. Indeed, however, when data for 2020 is eventually released by nations, the impact of COVID-19 may have significant impacts on these numbers like the 2008-09 financial crisis did.

Figure 3: Numeric data of NPL ratios for five selected data from 1998 to 2019

$\begin{array}{lccccc} & \text { Ukraine } & \text { Pakistan } & \text { Russia } & \text { Tunisia } & \text { Nigeria } \\ \mathbf{1 9 9 8} & 35.800 & 19.500 & 17.300 & 19.500 & 19.400 \\ \mathbf{1 9 9 9} & 35.800 & 22.000 & 13.400 & 18.800 & 25.600 \\ \mathbf{2 0 0 0} & 29.600 & 19.500 & 7.700 & 21.600 & 22.600 \\ \mathbf{2 0 0 1} & 25.100 & 23.400 & 6.200 & 21.000 & 19.700 \\ \mathbf{2 0 0 2} & 21.900 & 21.800 & 5.600 & 21.400 & 21.400 \\ \mathbf{2 0 0 3} & 28.300 & 17.000 & 5.000 & 24.200 & 20.500 \\ \mathbf{2 0 0 4} & 30.000 & 11.600 & 3.300 & 23.600 & 21.600 \\ \mathbf{2 0 0 5} & 57.990 & 8.300 & 2.600 & 20.900 & 21.600 \\ \mathbf{2 0 0 6} & 59.760 & 6.900 & 2.400 & 20.900 & 9.300 \\ \mathbf{2 0 0 7} & 48.120 & 7.600 & 2.500 & 20.900 & 9.500 \\ \mathbf{2 0 0 8} & 3.880 & 9.100 & 3.800 & 20.900 & 6.300 \\ \mathbf{2 0 0 9} & 13.700 & 12.200 & 9.530 & 13.200 & 37.300 \\ \mathbf{2 0 1 0} & 15.270 & 14.748 & 8.230 & 13.000 & 20.143 \\ \mathbf{2 0 1 1} & 13.470 & 16.207 & 6.590 & 11.300 & 5.772 \\ \mathbf{2 0 1 2} & 16.540 & 14.471 & 6.030 & 12.800 & 3.705 \\ \mathbf{2 0 1 3} & 12.890 & 12.987 & 6.000 & 14.500 & 3.393 \\ \mathbf{2 0 1 4} & 18.980 & 12.266 & 6.730 & 13.800 & 2.960 \\ \mathbf{2 0 1 5} & 28.030 & 11.359 & 8.350 & 14.500 & 4.861 \\ \mathbf{2 0 1 6} & 30.470 & 10.056 & 9.440 & 14.100 & 12.815 \\ \mathbf{2 0 1 7} & 54.540 & 10.000 & 10.000 & 14.300 & 12.820 \\ \mathbf{2 0 1 8} & 52.850 & 9.500 & 10.120 & 14.500 & 10.210 \\ \mathbf{2 0 1 9} & 48.400 & 9.100 & 16.900 & 14.600 & 9.300\end{array}$

Sources: Government-released treasury data; International Monetary Fund (IMF)

In all, the trend of NPL ratios and how governments address fluctuations in their national NPL ratios is an area of intense interest and debate. In the aftermath of the 2008-09 and heading into the new world after COVID-19, the NPL ratio of banks will be crucial to maintaining both financial stability and investment growth in countries.

\section{Methodology}

The methodology used in this paper seeks to use mathematical relations to investigate. In this section, many of the mathematical definitions and processes used in the results and findings section will be proved and explained, if necessary. This paper sets the loans that have already defaulted as the $\varphi$ variable. Thus, by 
definition, the total amount of nonperforming loans at a specific bank, represented by $\alpha$, would be all the non-performing loans of that bank summed. This is represented by the equation below:

$$
\alpha=\varphi_{1}+\varphi_{2}+\varphi_{3}+\ldots+\varphi_{n}
$$

However, NPL ratios include performing loans that are close to or at risk of defaulting, as well as reperforming loans that are close to or at risk of re-defaulting. Thus, the equation for the NPL ratios explored in this study also has to include that variable. If the variable $\varepsilon$ is set to represent a performing or reperforming loan that is at risk of becoming non-performing, then the total amount of these loans, represented by the variable $\beta$ can be expressed by the following equation below:

$$
\beta=\varepsilon_{1}+\varepsilon_{2}+\varepsilon_{3}+\ldots+\varepsilon_{n}
$$

All performing loans, as well as reperforming loans not at risk of defaulting and non-performing loans that are expected to become reperforming in the near future, can be represented by $\rho$ and the $\gamma$ variable representing the total amount. Thus:

$$
\gamma=\rho_{1}+\rho_{2}+\rho_{3}+\ldots+\rho_{n}
$$

To make the mathematical calculations later in this paper easier to understand, the variable $\omega$ is set to represent the total amount (both non-performing and performing) of loans at a given bank (or in a given economy) at any given time. Thus:

$$
\omega=\alpha+\beta+\gamma
$$

With these equations and variables above defined, it can be derived that $\partial=\frac{\alpha+\beta}{\omega}$ where $\partial$ is the NPL ratio of the bank and where $0 \leq \partial \leq 1$, which means that $\alpha+\beta \leq \omega$.

Using these equations, we can set $f(\alpha+\beta)$ as the function of total amount of effective non-performing loans at a bank and $\operatorname{set} f(\omega)$ as the function that defines the total amount of loans at the bank (nonperforming, performing, and reperforming). National treasuries often report NPL growth in percentage and relative growth rate. This is represented by $\mu$ in this paper. To calculate the absolute growth within a given period of time based on the growth rate, this formula must be used:

$$
\text { aggregate growth }=f(\alpha+\beta)_{i}
$$

Where $f(\alpha+\beta)_{i}$ is the initial amount of total non-performing loans, $f(\mu)$ is the growth rate of $\mu, n$ is the number of years in the time period, and $i$ is the number of additional doublings that the growth rate incurs, if any (due to outside influence). With these definitions proved, the rest of this following section will be dedicated to introducing (as well as proving) other theorems and formulas used in paper's results/findings section.

It should also be noted that the above equations can be summarized for simple NPL cases by the following:

$$
\begin{gathered}
\text { Assuming } x=\alpha+\beta ; y=\omega ; \text { and } z=f(\mu) \\
\downarrow \\
x=\alpha+\beta=\varphi_{1}+\varphi_{2}+\varphi_{3}+\varepsilon_{1}+\varepsilon_{2}+\varepsilon_{3}+\ldots+\varphi_{n}+\varepsilon_{n}
\end{gathered}
$$




$$
\begin{gathered}
\downarrow \\
\partial=\frac{\alpha+\beta}{\omega}=\frac{x}{y} \\
\downarrow \\
\text { simple NPL aggregate growth }=f(x)+\text { rate of growth of } f(x)
\end{gathered}
$$

The simple rate of growth for the aggregate growth rate would be simply the derivative

The above expression written out verbally would be:

$$
\text { Simple NPL Ratio }=\frac{\text { total defaulted loans }+(\mathrm{re}) \text { performing loans at risk of defaulting }}{\text { total amount of loans at bank }}
$$

A simple calculation of the above statement is found commonly in this paper. For example, a bank that has a portfolio of $\$ 600$ million. The bank has $\$ 80$ million worth of non-performing loans and an additional $\$ 25$ million worth of performing loans that are at risk of becoming non-performing. Its simple NPL ratio would be:

$$
\text { Simple NPL Ratio }=\frac{\$ 80,000,000+\$ 25,000,000}{\$ 600,000,000}=\frac{\$ 105,000,000}{\$ 600,000,000}=0.175=17.5 \%
$$

The main calculation done in this paper will include or choose to not include units per the situation revolving the problem at hand. If the problems does call for it, it will do.

This method of calculation will be used to derive all NPL ratios in this paper unless another method is otherwise stated. Mathematical reasoning and work may be grouped into one step as repeating the same work complicates the mathematics in the paper.

With all the examples and mathematical definitions and proofs given, the next section will cover a review of literature in the topic of NPL ratios and previous research done on the topic. Please note that this method will not be repeated in subsequent sections, all mathematical work done will be based on simple assumptions, logic, and the methods presented in this section. If a new method arises but was not introduced in this section, a short introduction will be made (but that method most likely will not be relevant).

\section{Literature Review}

The topic of high NPL ratios in national economies has been the focus of many research projects across the world in recent years. The relationship between NPL ratios and the overall health of a national economy is well-established; a meta-analysis by a team of researchers in 2019 led by Professor Shihadeh, Gamage, and Hannon clearly showed the relationship between the increasing NPL ratios in select countries and the impact they had. In addition to that study, multiple studies conducted at universities around the world point to the fact that a high NPL ratio is a primary indicator for bank failure. If taken at the macroscopic view, a national economy that has a high NPL amount when compared to the total loan or even nominal GDP has been shown through research to indicate a weaker economy that is at greater risk to a recession than normal economies. 


\section{Results and Findings}

The results and findings of this study is separated into two major sections. The first of which summarizes the findings based on data presented in the Introduction, methods introduced in afterwards, as well as data that has yet been presented (but will be introduced late in this section). The second section introduces supporting graphics and data which backs up claims made not only in this section but in previous ones as well.

Using the data provided in the initial introduction to this paper, as well as other sources and original findings, a conclusion of the following impact of high NPL ratios can have on an individual bank's lending trends and profitability is below (in no specific order):

1. High NPL ratios cause a contraction in bank credit supply.

2. Short-term loans are significantly favored over long-term loans.

3. Increased risk of bank shutdown or failure.

4. Distorted credit allocation; imbalance of credit spread in the bank.

5. Decreased number of loaners and customers registering at the bank.

A high NPL ratio also has impacts on the national economy, through data presented above as well as graphs and logistics presented below, the impact of high NPL ratios can have on an entire national economy is given below (in no specific order):

1. Drastic decrease in market confidence.

2. Significant decrease in total amount of loans given out in the aftermath.

3. A significant contraction in national loan supply.

4. Slows economic growth and impacts rate of nominal GDP growth.

5. National banks and treasuries have heightened responsibility to not only support local banks but also actively decrease the high NPL ratios present.

With the impact of high NPL ratios summarized, this study also found (from data and experts) that the main impact of national governments decreasing high NPL ratios has a significant impact on the national economy - almost always a positive impact for that.

1. Economies experience an influx of new credit supply.

2. Previously distorted credit allocation becomes undistorted.

3. Significant uptick in the rate of credit growth.

4. Improved confidence in the overall health of the national economy.

5. Significantly improved

The paper found a statistically significant relationship between changed lending trends of a bank and high NPL ratios. Specifically, banks tended to decrease the total amount of loans as well as switch types of loans to make loaning safer for their profits. It is also found that a bank's profitability suffers when their NPL ratios increase beyond a point.

Figure 4: Numeric data of NPL ratios for five selected data from 1998 to 2019

Source: International Monetary Fund (IMF)

The above map shows the exact variance of NPL ratios of selected countries highlighted. The later text will make references to Figure 5 as well as the graph presented below:

Figure 5: Greek NPL Ratio (as a percentage) from 2000 to 2019 


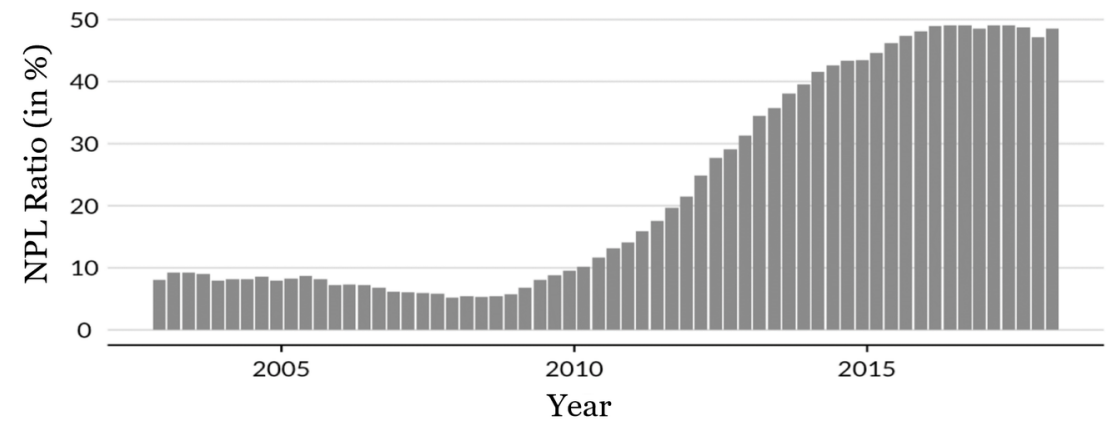

Source: International Monetary Fund (IMF); National Bank of Greece (NBG)

An interesting phenomenon occurs when countries with fallacies in their economic policies are compared with countries with strong backing of economic policies or plans to reduce NPL ratios and keep them under control.

Figure 6: NPL Ratios Data for Russia, Ukraine, Canada, and the US in 2000, 2010, and 2019

\section{[CHART $]$}

Source: International Monetary Fund (IMF); Central Bank of Russia; National Bank of Ukraine; National Bank of Canada; United States Department of Treasury

As seen in this Results section and the preceding sections and data presentation, the national economic policy, combined with adequate plans to reduce NPL ratios when it becomes too high or becomes out of control, is essential to keeping a healthy level of NPL ratio in the economy. If the NPL ratio becomes too high, there are many consequences (as discussed in this section). The high NPL countries will need to adopt economic policies that can properly lower the national NPL ratio, otherwise both their economic growth as well as the commercial banking sector will be damaged. Many of these countries' problems originated at the end of the 2008-09 financial crisis and have not recovered. Even countries like the US experienced an upsurge in its NPL ratio, but some countries recovered better from the surge than others. This was mainly due to a combination of plans to decrease the NPL ratio as well as control over the commercial banking sector to allow recoveries to occur quickly yet naturally over the course of years.

It is important to note the potential impact of the COVID-19 pandemic and how that may impact the NPL ratios of not only banks in pandemic breakout regions but as well as countries suffering from the economic and social reel back of the pandemic. The responses to COVID-19 has varied from country to country, but the general expected trend is for NPL ratios to go up in COVID-19 impacted regions. This follows the logic that loaners are not able to pay back their loans with the COVID-19 induced financial stress. If loaners are not able to pay back, the loans become non- performing - thus causing the rate to rise. If nations are able to effectively hand out a plan that gives stimulus incentives to banks, loaners, or both, the NPL ratio may be maintained at a healthy level that does not involve the national NPL ratio to rise significantly after COVID-19. This, however, may not necessarily solve the issue of at the local bank level.

The COVID-19 pandemic may also exacerbate already high NPL ratios in economies like Russia, Ukraine, and the like. These consequences combined with the leftover high ratios from the 2008 to 2009 financial crisis may make it even more difficult to recover. These governments will need smart planning and sensible economic policies in order to facilitate a partial or full recovery from not only the COVID-19 pandemic socially, but also in their non-performing loan amount and how much they can make in profits.

It is also important to mention findings about the effectiveness of government regulations. It is found that handing out incentives for banks during recessional periods allows the ratio to stay down by ensuring the banks are still able to keep an even spread on their loan types. It also helps to decrease the ratio if national 
governments give incentives to their citizens to take out loans. This includes tax cuts or even cash incentives that allow citizens to take out loans and get a reward for that action. Indeed, the paper found that the more effective government comes from giving incentives.

\section{Conclusion}

This study has shown that the economies with higher NPL ratios are more prone to economic consequences and repercussions that economies with lower NPL ratios are less at risk of. It has also shown that high NPL ratios damage both individual banks as well as the national economy if too many banks in a country has unnaturally high ratios. Non-performing loans plays a key role in not only bank functioning but also maintaining confidence in the market, how credit is allocated in the country, all the loans given out, the total amount of loans available, as well as the risk of possible credit distortion. Countries that can maintain low levels of NPL ratios receive benefits such as increased market confidence, an even spread of credit supply, and large supply of loans. Nations that work actively to decrease a high NPL have been shown to have significant positive long-term results that includes boosting bank loaning and lending behavior to increase the total amount of loans. Indeed, a low non-performing loan ratio is beneficial to not only the bank but also to the citizens and governments and the overall economy. Governments and lawmakers around the world draft different ways to maintain low NPL ratios as well as bring them down when needed to, and that trend should continue.

\section{References and Sources}

Ari, Anil, et al. The Dynamics of Non-Performing Loans during Banking Crises: a New Database . Apr. 2020, www.ecb.europa.eu/pub/pdf/scpwps/ecb.wp2395 834e0e7137.en.pdf.

"Bank Nonperforming Loans to Total Gross Loans (\%)." Data , 2020, data.worldbank.org/indicator/FB.AST.NPER.ZS.

"Bank-Specific Factors Affecting Non-Performing Loans in Developing Countries: Case Study of Indonesia." :: The Journal of Asian Finance, Economics and Business :: 2020, jafeb.org/journal/article.php?code=61553.

"COVID-19 and Non-Performing Loans." VOX, CEPR Policy Portal , 2020, voxeu.org/article/covid-19and-non-performing-loans.

"Non Performing Loans Are Increasing in Many European and Sub-Saharan African Economies." WDI - Non Performing Loans Are Increasing in Many European and Sub-Saharan African Economies , datatopics.worldbank.org/world-development-indicators/stories/non-performing-loans-are-increasing-inmany-european-and-sub-saharan-african-economies.html.

Panta, Bishop. Non-Performing Loans and Bank Profitability: Study of Joint Venture Banks in Nepal . 28 Oct. 2019, papers.ssrn.com/sol3/papers.cfm?abstract_id=3304961.

Khan, Muhammad Asif, et al. "Determinants of Non-Performing Loans in the Banking Sector in Developing State." Asian Journal of Accounting Research , 24 Apr. 2020, www.emerald.com/insight/content/doi/10.1108/AJAR-10-2019-0080/full/html.

Louzis, Dimitrios P., et al. "Macroeconomic and Bank-Specific Determinants of Non-Performing Loans in Greece: A Comparative Study of Mortgage, Business and Consumer Loan Portfolios." Journal of Banking $\mathscr{E}$ Finance, North-Holland, 25 Oct. 2011, www.sciencedirect.com/science/article/abs/pii/S0378426611002895. 
Saba, Irum Saba, et al. "Determinants of Non Performing Loans: Case of US Banking Sector." CiteSeer X , June 2012, citeseerx.ist.psu.edu/viewdoc/download?doi=10.1.1.261.1833.

Zimmermann, and Nighat BILGRAMI-JAFFERY*. "Research Notes Non-Performing Loans: Determinants and Impact on Banking Industry, by Nighat BILGRAMI-JAFFERY*." Pakistan Journal of Applied Economics , Applied Economics Research Centre, 1 Jan. 1970, ideas.repec.org/a/pje/journl/article15sumiii.html. 